\title{
Perancangan Robot Pengikut Garis Sederhana Sebagai Perangkat Pelatihan Tingkat Pemula
}

\author{
Dwi Astharini*, Rona Regen, Nasrullah, Ibrahim, Surya Agam \\ Program Studi Teknik Elektro, Fakultas Sains dan Teknologi, \\ Universitas Al Azhar Indonesia, Jl. Sisingamangaraja, Jakarta 12110 \\ *Penulis untuk Korespondensi: astharini@uai.ac.id
}

\begin{abstract}
Abstrak - Tulisan ini melaporkan perancangan robot sederhana pengikut garis. Dalam hal ini hasil rancangan akan digunakan sebagai perangkat pelatihan siswa sekolah menengah, sehingga rancangan dibatasi pada fungsi minimumnya agar pembuatan dapat dilakukan secara in house. Perangkat keras dibangun menggunakan photodioda dan LED IR pada sistem sensor, ATMega16 sebagai pengendali utama dan PCB buatan sendiri
\end{abstract}

Abstract - Design of a simple line follower robot is reported in this paper. In order to meet the needs on training for school student, the design is restricted to have just the minimum function so that the implementation can be done in house. The hardware built utilizes photodiodes and IR LED as sensor system, ATMega16 as main controller and manually made PCB.

Keywords - Simple Line Follower, photo diode, PCB design, microcontroller

\section{PENDAHULUAN}

$\mathrm{R}$ obotika secara universal telah terpilih menjadi salah satu contoh teknologi untuk diperkenalkan secara dini di masyarakat. Saat ini robotik digunakan dan dipelajari dalam tingkatan yang luar biasa beragam, dari yang dapat dirakit oleh anak usia dini sampai robot kompleks yang hanya dibuat untuk keperluan tertentu misalnya di ruang angkasa.

Pada tingkat awam, berbagai perusahaan mainan menyediakan perangkat siap rakit berikut program yang telah diisi sehingga hanya membutuhkan perintah sederhana untuk mengoperasikannya. Untuk memperkenalkan teknologi robot yang lebih mendalam pada tulisan ini dikemukakan pengembangan suatu robot sederhana namun secara menyeluruh. Proses yang dilakukan mencakup pemilihan dan uji komponen, perancangan dan pembuatan rangkaian dan $\mathrm{PCB}$, dan pemrograman mikrokontroler. Line Follower robot dipilih karena fungsinya yang sederhana dan menewarkan banyak kebebasan dalam kreatifitas maupun tingkat pembuatannya [1][2].

Pada bagian setelah ini dijelaskan proses pengembangan yang dilakukan. Selanjutnya tulisan disusun berdasarkan tahapan pengembangan, yaitu rancangan sistem besar pada bagian ketiga, pemrograman pada bagian keempat, bagian elektronika pada bagian kelima, diakhiri penutup.

\section{TINJAUAN PUSTAKA}

Pustaka [1] adalah referensi utama pekerjaan ini sebagai robot yang dikembangkan pada lab yang sama. Sistem yang dikembangkan di sini menitikberatkan pada sensor dan pengkondisi sinyal, sistem mikrokontroler sebagai pengendali keseluruhan serta bagian mekanik yang dikendalikan. Diagram blok sistem dapat dilihat pada gambar 1 .

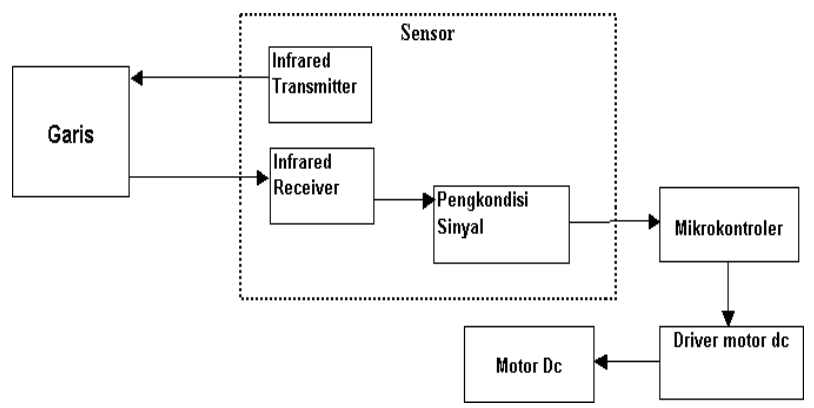

Gambar 1. Diagram blok sistem [1] 
Sebagai penjejak garis, robot membutuhkan sensor untuk menentukan jalannya. Ada beragam pilihan sensor yang dapat digunakan, pada [1] maupun [2] dipilih photo dioda sebagai sensor penentu garis. Prinsip kerjanya sederhana, hanya memanfaatkan sifat cahaya yang akan dipantulkan jika mengenai benda berwarna terang dan akan diserap jika mengenai benda berwarna gelap. Sebagai sumber cahaya digunakan LED inframerah. Gambar 3 menunjukkan ilustrasi kerja sistem sensor ini, yaitu pada warna gelap, penyerapan cahaya lebih besar daripada warna putih, sehingga cahaya yang terpantul ke sensor menjadi lebih kecil.
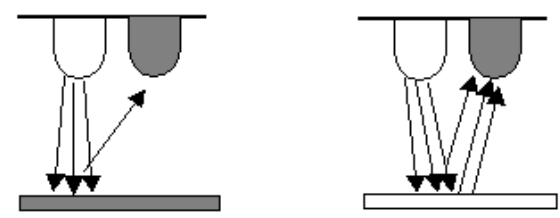

Gambar 2. Ilustrasi kerja sistem sensor garis [1]

Pada [1] digunakan 8 pasang LED-photodioda yang disusun dalam 2 barisan sederhana. Pada [2] dikatakan bahwa jarak antar sensor sebaiknya diatur sesuai lebar garis yang akan diikuti. Jika garis tipis jarak sensor harus dikurangi, agar pada belokan robot dapat berbelok pada waktunya. Pada pustaka ini kedelapan pasangan sensor disusun dalam bentuk matriks 3-2-3.

\section{METODOLOGI PENELITIAN}

Pembahasan Metodologi dibagi mengenai alur proses dan rancangan umum.

\subsection{Alur Proses Pengembangan}

Pengembangan robot pengikut garis pada kegiatan ini dilakukan sesuai diagram alur pada gambar 3 .

Tahapan dimulai dengan penentuan spesifikasi berdasarkan tipe robot, di antaranya misalnya bahwa robot yang dibuat akan mengikuti garis berwarna hitam atau gelap pada lahan putih atau terang. Tahapan rancangan mekanis dan sensor akan dibicarakan pada bagian ketiga setelah ini, sementara bagian keempat mengangkat tahapan selanjutnya mengenai mikrokontroler dan pemrograman. Disain dan pembuatan bagian elektronik dapat dilihat pada bagian kelima tulisan ini.

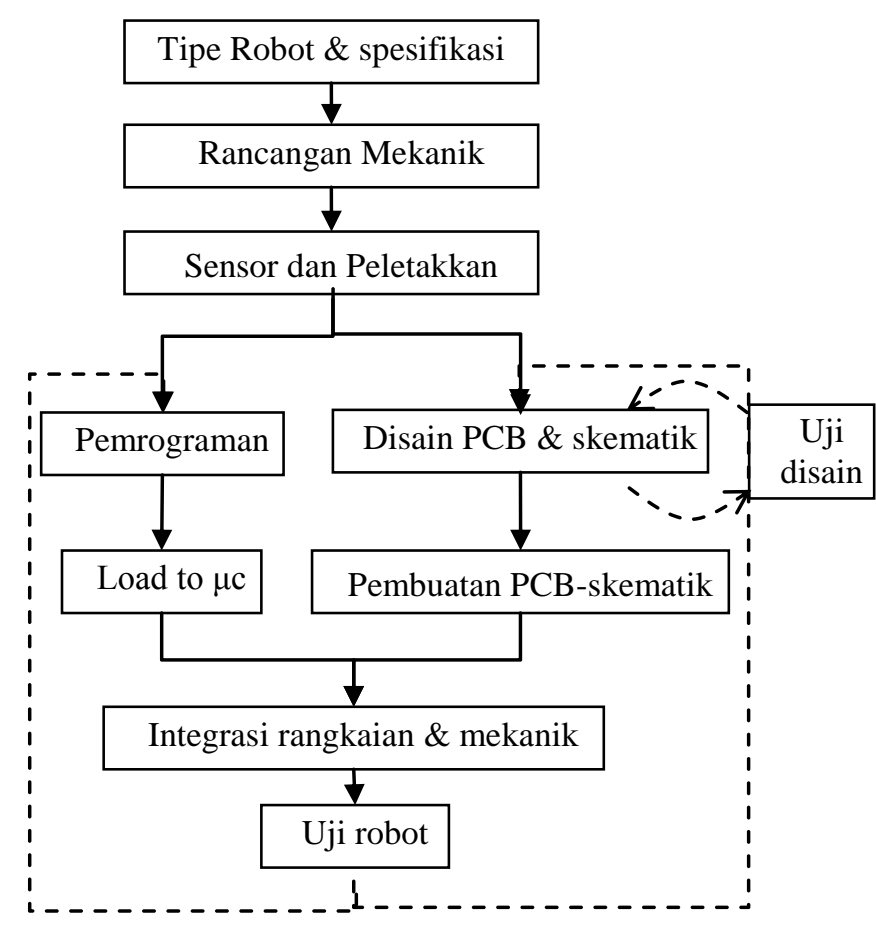

Gambar 3. Alur proses pengembangan robot

Garis iterasi ke kiri pada diagram menuju pada proses pemrograman mikrokontroler yang memang dapat dilakukan berulang pada sistem yang sudah terintegrasi tanpa banyak perubahan pada bagian lainnya. Sementara garis iterasi ke kanan memberikan implikasi perubahan perangkat keras meski dalam hal ini dibatasi pada bagian elektronika saja.

\subsection{Spesifikasi dan Batasan Perancangan}

Pada pengembangan ini perhatian lebih banyak diberikan pada bagian elektronika dan pemrograman, sesuai latar belakang tim yang bekerja. Untuk bagian mekanik banyak menggunakan rancangan dari [1], dengan beberapa modifikasi dan simplifikasi pada pemilihan komponen serta penempatannya. Dalam hal ini sesuai prinsip tulisan, rancangan dibuat secara sederhana, dalam artian seluruh komponen diusahakan terlihat dan dapat diakses dengan mudah. Hal ini iperlukan agar pengguna yang merupakan pemula dapat mempelajarinya dengan cepat, sekaligus memudahkan dalam penggantian komponen.

Untuk mendeteksi garis digunakan sensor yang terdiri atas 8 pasang IR LED dan photodiode, disusun dalam formasi busur dengan jarak antar sensor dengan yang lainnya lebih kecil dari lebar 
garis. Formasi bentuk ini dapat mendeteksi garis lintasan dengan lebih baik terutama pada belokan daripada formasi sensor garis lurus.

\section{HASIL DAN PEMBAHASAN}

Hasil kegiatan adalah rancangan robot pengikut garis sederhana sesuai tujuan di depan. Pada bagian ini dipaparkan proses perancangan dan pembuatan robot, terbagi atas bagian pemrograman dan bagian perangkat keras.

\subsection{Pemrograman Mikrokontroler}

Pemrograman dilakukan berbasis $\mathrm{C} / \mathrm{C}++$ menggunakan Codevision AVR, yang merupakan interpreter ke Assembly. Setelah debugging selesai program baru di-load ke $\mu \mathrm{c}$. Mikrokontroler yang digunakan adalah ATMega16 yang memiliki fasilitas ADC internal dan memori $16 \mathrm{~kb}$. Seri ATMega ini dipilih karena harganya yang relatif murah dan posisi pin outputnya berurutan sehingga lebih memudahkan rancangan elektroniknya, cocok untuk prinsip minimalis yang diinginkan.

Proses pengambilan data masukan berasal dari pembacaan dari sensor sensor garis. Data dari pembacaan sensor garis kemudian diolah dalam program utama menjadi suatu keputusan untuk memilih satu dari beberapa jenis pergerakan yang ada. Untuk robot sederhana ini hanya ada tiga gerakan yang diprogram, yaitu maju, balok kiri dan belok kanan.

Metode pembacaan data sensor yang digunakan adalah pengkodean logika tinggi jika terdeteksi warna putih dan logika rendah jika terdeteksi warna hitam. Sehingga pegkodean tersebut bersifat aktiv low. Pembacaan data sensor sangat berpengaruh terhadap pergerakan robot pendeteksi garis.

\subsection{Rancangan dan Pembuatan Bagian Elektronik}

Seluruh bagian elektronik pada tulisan ini dirancang dan dibuat sendiri dalam pengerjaan menggunakan fasilitas Laboratorium Teknik Elektro UAI. Pada bagian inilah simplifikasi terutama dilakukan, agar rancangan mudah dipahami bagi pemula.

Perancangan skematik dan PCB dilakukan menggunakan piranti Proteus. Piranti ini dipilih karena memiliki fasilitas perancangan baik untuk skematik (Isis) dan PCB (Ares), dilengkapi dengan pengujiannya secara simulasi. Hasil rancangan ditampilkan pada gambar 4-7.

Penempatan sensor formasi busur dapat dilihat pada Lay out PCB sensor pada gambar 4. Lingkaran D1 sampai D16 menunjukkan pasangan IR LED dan photodioda yang digunakan. PCB sensor ini pada rancang nyabangun diletakkan di bagian depan bawah robot

Rancangan kemudian diimplementasi sebagai perangkat keras dalam bentuk dua buah PCB, yang keseluruhan dibuat di Laboratorium Teknik Elektro UAI. Pembuatan secara inhouse ini dimungkinkan berkat disain rangkaian yang sederhana. Selain itu ukuran PCB yang dibuat cukup besar untuk dikerjakan secara manual. Lembaran akhir PCB yang siap diintegrasi ke sistem memiliki dimensi $6 \times 7 \mathrm{~cm}^{2}$ untuk sistem mikroprosesor, serta $8 \times 10$ $\mathrm{cm}^{2}$ untuk sistem sensor.

Kedua lembaran PCB yang telah siap diintegrasikan dengan bagian mekanik robot setelah sebelumnya dilengkapi dengan mikrokontreler yang telah diisi program.

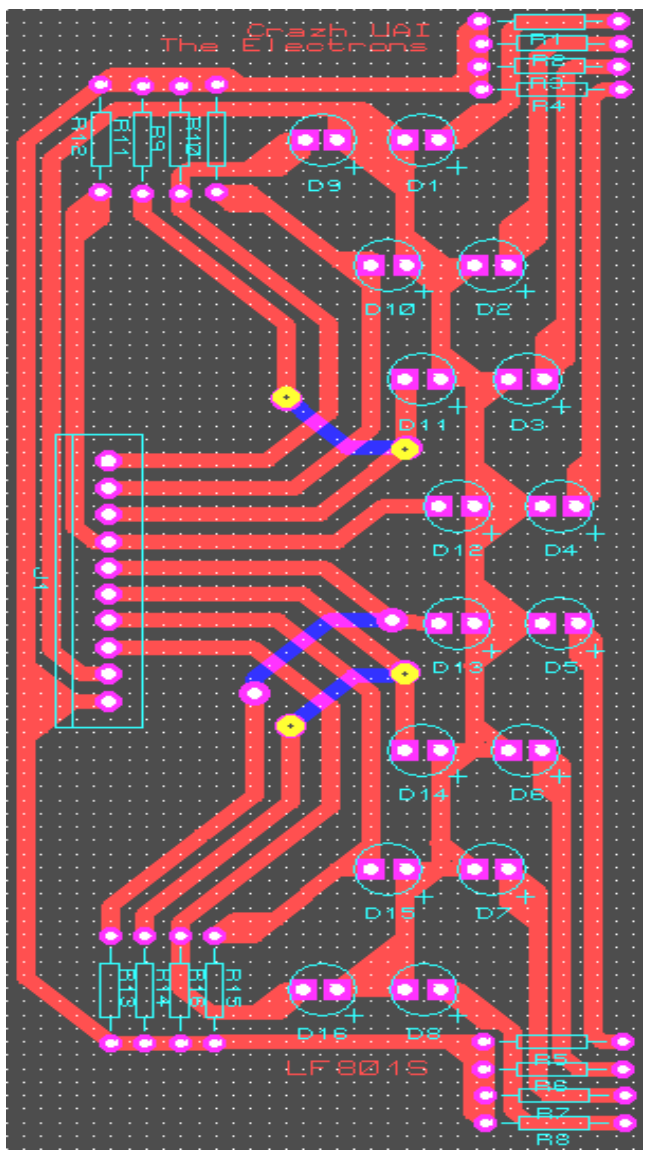

Gambar 4. Lay out PCB sensor 


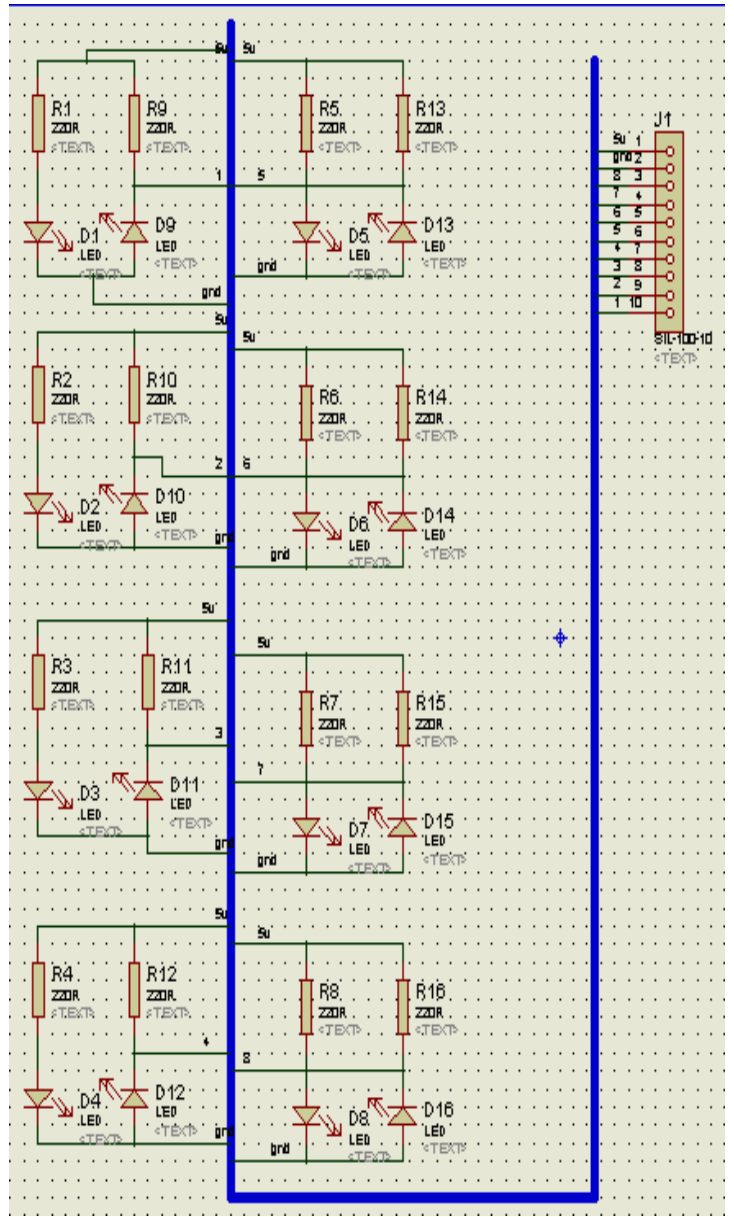

Gambar 5. Diagram Skematik sensor

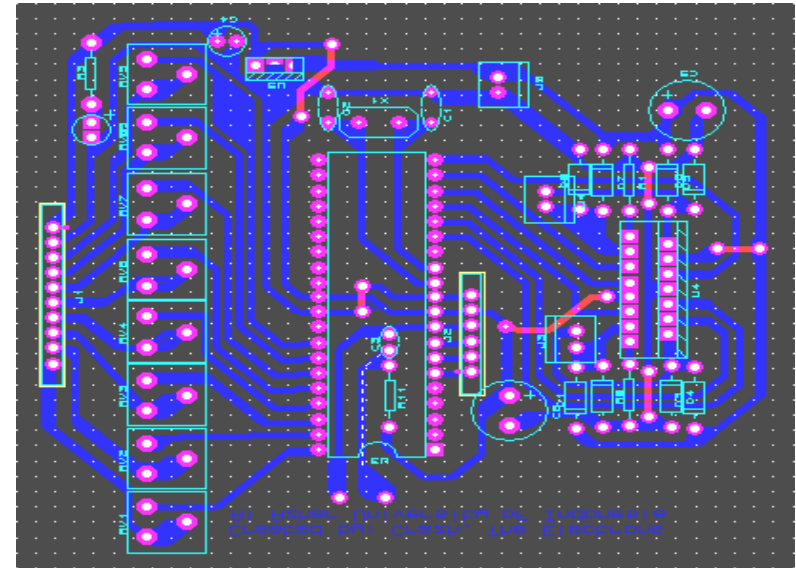

Gambar 6. Lay out PCB sistem mikroprosesor

\section{KESIMPULAN}

Pada tulisan ini telah dipaparkan perancangan robot line follower yang cukup sederhana untuk digunakan sebagai model sekaligus materi pada pelatihan tingkat pemula.

Rancangan di atas telah diimplementasi sebagaimana terlihat pada gambar 8 .

Prinsip sederhana dituangkan dalam pemilihan komponen dan pengaktifan fungsi, sehingga dihasilkan robot bersifat minimalis. Rancangan yang sederhana tersebut lebih memungkinkan pembuatan robot secara inhouse terutama pada bagian elektronika.

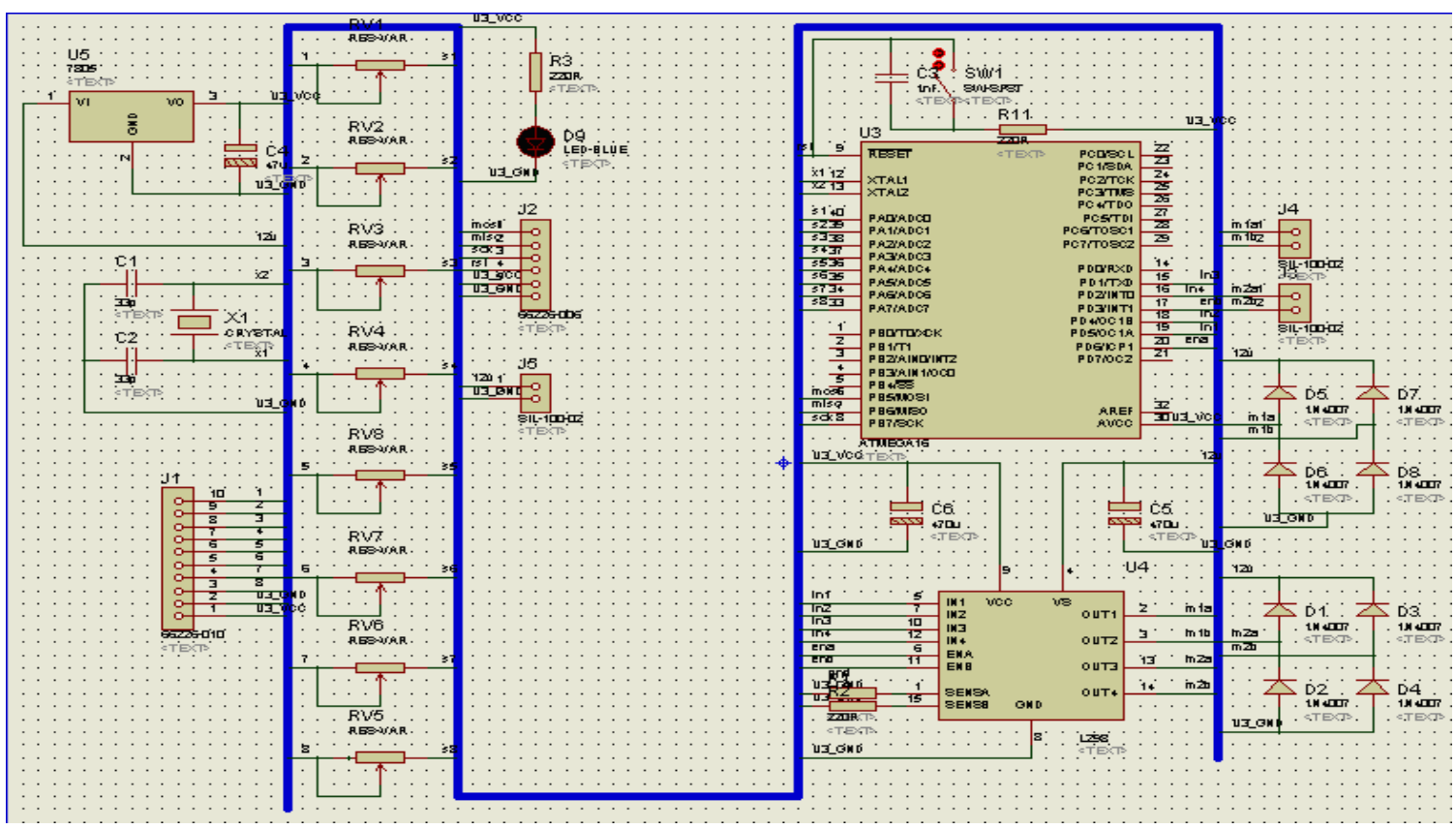

Gambar 7. Diagram Skematik sistem 

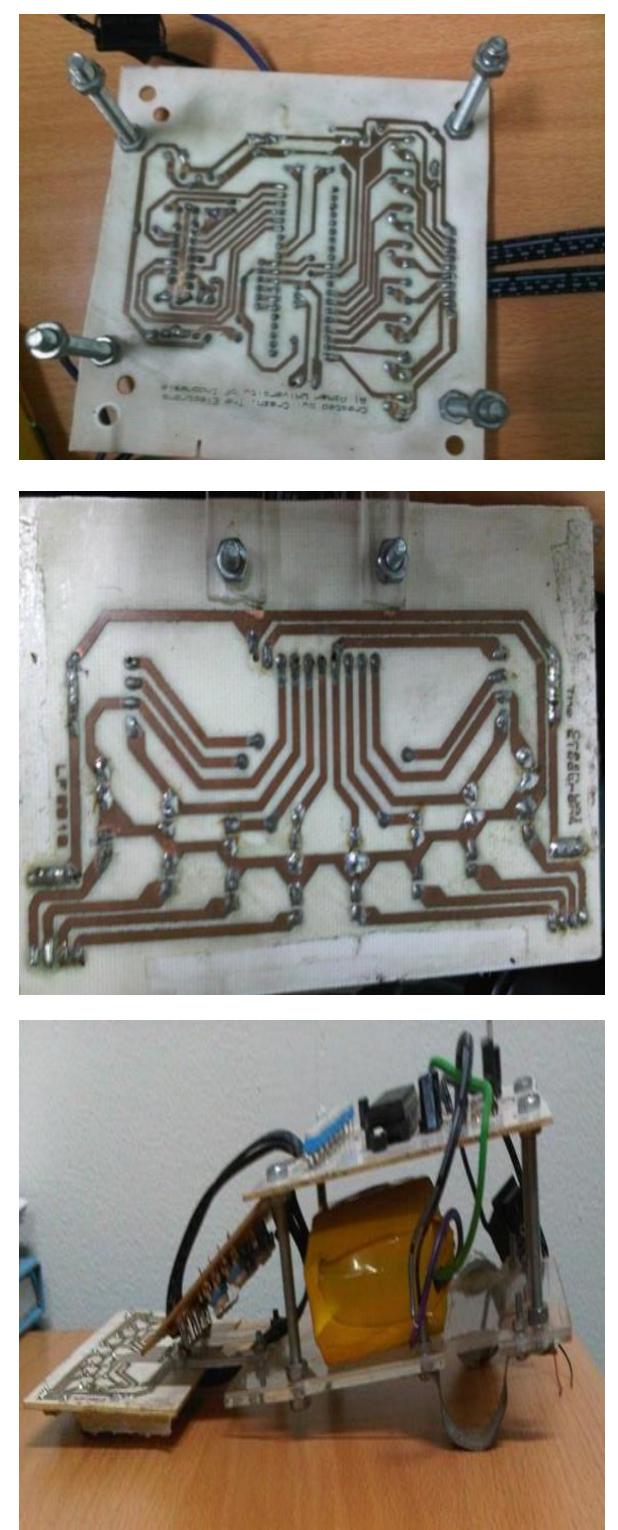

Gambar 8. Dari Atas ke Bawah : panel mikroprosesor; panel sensor; sistem terintegrasi

\section{DAFTAR ACUAN / PUSTAKA}

[1] Riswo, Yaya Suryana, Anwar Mujadin, "Robot Pengikut Garis menggunakan Sensor Infra Merah berbasis Mikrokontroler AVR Atmega 8535", Prosiding Sains dan Teknologi, FST UAI, Ed Oktober 2010.

[2] Pakdaman, M.; Sanaatiyan, M.M.; Ghahroudi, M.R.; "A line follower robot from design to implementation: Technical issues and problems"; Proceedings of 2nd International Conference ICCAE, Vol. 1 pp. 5-9, IEEE Publications, 2010.

[3] Hadian Permana, "Closed-loop Control of Brushed DC Motor using PID and Fuzzy Logic", Thesis, Faculty of Mechatronics, SGU 2005.

[4] "ATMEL ATMega16" Datasheet ATMEL corporation. 